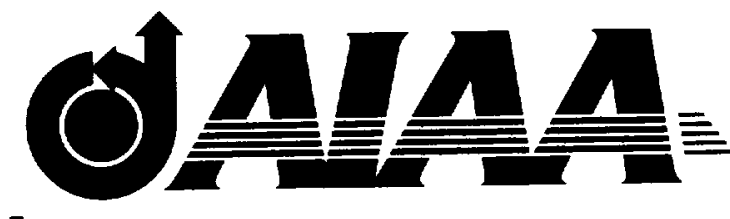

\title{
AIAA 2001-2421 PARAMETER SENSITIVITY STUDY OF THE WALL INTERFERENCE CORRECTION SYSTEM (WICS)
}

Eric L. Walker and Joel L. Everhart NASA Langley Research Center, Hampton, VA 23681

Venkit lyer

Lockheed Martin, Hampton, VA 23681

\section{9th AIAA Applied Aerodynamics Conference June 11-14, 2001/Anaheim, CA}




\title{
PARAMETER SENSITIVITY STUDY OF THE WALL INTERFERENCE CORRECTION SYSTEM (WICS)
}

\author{
Eric L. Walker and Joel L. Everhart ${ }^{\dagger}$ \\ NASA Langley Research Center, Hampton. VA 2.3681 \\ Venkit Iver \\ Locklied Martin. Hampton. VA 23681
}

\begin{abstract}
An off-line version of the Wall Interference Correction System (WICS) has been implemented for the NASA Langley National Transonic Facility. The correction capability is currently restricted to corrections for solid wall interference in the model pitch plane for Mach numbers less than 0.45 due to a limitation in tumnel calibration data. A study to assess output sensitivity to the aerodynamic parameters of Reynolds number and Mach number was conducted on this code to further ensure quality during the correction process. In addition, this paper includes an investigation into possible correction due to a semispan test technique using a non metric standoff and an improvement to the standard data rejection algorithm.
\end{abstract}

\section{Nomenclature}

(b) Nondinensional drag coefficient

$C_{l}$ Nondimensional lift coefficient

M Nach number

P Pressure

Re Reynolds number per unit length

I. Axial velocity determined by calibration

$U_{x} \quad$ Free-stream velocity

$u_{i}, u_{i}, w_{i}$ Velocity perturbations: $x, y_{2} z$ components

r.y,z Cartesian body axes

a Angle of attack

3 Angle of sideslip)

$\unlhd$ Correction

* Research Encineer. Research Facilities Branch, Aerodynamics. Aerothermodynamics, and Acoustics competency. Student Vember AIAA.

${ }^{\dagger}$ Research Engineer, Research Facilities Branch, Aerodynamics. Derothermodymamics, and Acoustics Comperency Sentor Aember AlA.

tAeronautical Engineer. Senior Member NIAA.

Copsright (1) 2001 by the Americaul Institute of Aeronanties and Astronautics, lnc No copvright is asserted in the Enited states under Title 17 . L.S. Code. The U.S. Cowernuent has a ruyalty. free license to exercise all rights under the coppright rlaimed herein for Governmental Purposes. All wher rights are reserved by the copvright owner. $\varphi \quad$ Velority potential

$\begin{array}{ll}\text { Subscripts } \\ \text { rorr } & \text { Corrected } \\ F & \text { Free ali } \\ i & \text { incremental correction } \\ \text { so } & \text { semispan standoff } \\ T & \text { In tumnel } \\ u n c & \text { Cncorrectod } \\ \infty & \text { Freestream }\end{array}$

\section{Introduction}

The subject of wall interference has broadened inmensely over the past century. Classical correction methods for this effect incorporate a mathematical boundary condition for the wind tumnel walls. Nondimensional parameters have been tabulated and a number of formulas to correct spatially-varying wallinterference for aircraft-like models have been derelmented in texts such as AGARDograph 109.' More often facilities are testing in regions that exceed the design specifications of the facility. Increased model size, for instance. may introduce larger amounts of blockage and lift interference than the classieal methods can properly handle. Modern, more rapable intefference-correction methods, including beundary pressure methods were recently published in AGARDograph 336." The advantage of the boundary pressure methods over classical methods is their ability to respond to the actual conclitions of the flow in the tumncl test section; additionally: boundary pressure methods are more complex than classical methods but can be implemented for online post-point/post-scan applications.

Customers are also placing more stringent accuracy requirements on the acquired data. To reduce the uncertainties introduced in tunnel clata due to the presence of the walls. thereby enhancing data quality. NASA Langley Research Center has implemented the 
Wall Interference Correction System (WICS) for solid wall testing in the National Transonic Facility (NTF). ${ }^{3}$ The code was originally developed by Clbrich et al. ${ }^{4}:$ at NASA Ames Research Center for the 12-Foot Pressure Wind Tumnel. The WICS code uses a modified Hackett (Wall Signature) Method to determine wall interference corrections. This method was selected because it is rapid and robust, and it has minimal impact on the facility in terms of instrumentation when compared to other boundary pressure methods. A brief description of the theory behind the WICS method and the implementation at the NTF is presented.

The purpose of this paper is to determine code output sensitivities to acrodynamic parameters, support systems, and other input parameters for both semispan and fullspan models. These cases will be summarized for application during operational use of the WICS code.

\section{Correction Accuracy Requirements}

Before a sensitivity study can be conducted on the WICS code, it is necessary to mnderstand the accuracy requirements placed on wall interference corrections in gemeral. According to Steinle and Stancwsky, ${ }^{10}$ the requirements for transonic cruise are dominated by a one count $\left(C_{D}=0.0001\right)$ accuracy for drag for a transport-type aircraft. Since the WICS code is not used exclusively on transport-type aircraft in cruise, a more general requirement is nerded. Newman and Evcrhart ${ }^{2}$ report the accuracy requirements listed below in Table 1.

\begin{tabular}{|c|c|c|}
\hline Type of Test & Incremental & Absolute \\
\hline High Lift & $0.2 \% C_{L} \& C_{D}$ & $0.4 \% C_{L} \& C_{D}$ \\
\hline Transonic & $1 / 2$ count $\left.C_{D}\right)$ & 1 count $C_{D}$ \\
\hline
\end{tabular}

Table 1 Generalized Industry Correction Accuracy Requirements

\section{Description of the NASA LaRC National Transonic Facility}

The NTF ${ }^{11}$ is a fant-driven, closed-circuit, continuous-flow. pressurized wind tumnel, which is capable of testing at cryogenic conditions. The test gas is dry air for elevated temperature operation and nitrogen for reduced temperature operation. The settling chamber contains four anti-turbulence screens. A 15:1 contraction ratio entrance cone leads into an 8.2 feet square cross sectional test section with six inch triangular corner fillets which extends 25 feet in length then opens into a high speed diffuser. The operational envelope of the NTF encompasses a large range of test conditions. The facility can sustain a continuous airspeed from 0.1 to 1.2 in Mach number. Total pressure capabilities of the facility range from 15 to $130 \mathrm{psi}$. The tunnel can operate at temperatures ranging from $150^{\circ} \mathrm{F}$ down to $-320^{\circ} \mathrm{F}$. These large ranges of conditions allow Reynolds munber testing from 3 to 120 million per foot. NTF has the capability to independently vary Mach number, Reynolds number, and dynamic pressure.

Both fullspan and scmispan model mounting systems are arailable in the NTF. Fullspan models are supported by an aft mounted sting. This sting is attached to a vertically oriented arc sector used to change model pitch attitude over a range from $-11^{\circ}$ to $19^{\circ}$. The roll mechanism has a range of $-90^{\circ}$ to $180^{\circ}$. Sirleslip angles are achieved by using combined roll and pitch angles. A sidewall mounting srstem is used for semispan models. The angle of attack range is $\pm 180^{\circ}$. The center of rotation for semispan and fullspan models is tumnel station 13 fert.

Currently, the NTF has 459 operational wall pressure orifices of which the WICS code uses 360 . Looking downstream. Figure 1 shows the cross sectional diagram of the rows of pressure ports; it also serves as a map between the NTF row numbering scheme and that used for WICS. Figure 2 urw wraps the tumnel walls to show the current wall orifice lavout. The filled port symbols arc an example subset of port selections used for WICS:

\section{The Wall Interference Correction System (WICS)}

The following presents a brief overview of Ulbrich s extension of the Harkett wall signature method. including theory and the current implementation of WICS in the NTF. A more detailed description is given by Ulbrich et al. ${ }^{4-9}$ and Iyer et al. ${ }^{3}$ The method applies a measured pressure boundary condition which is the tared difference between the model

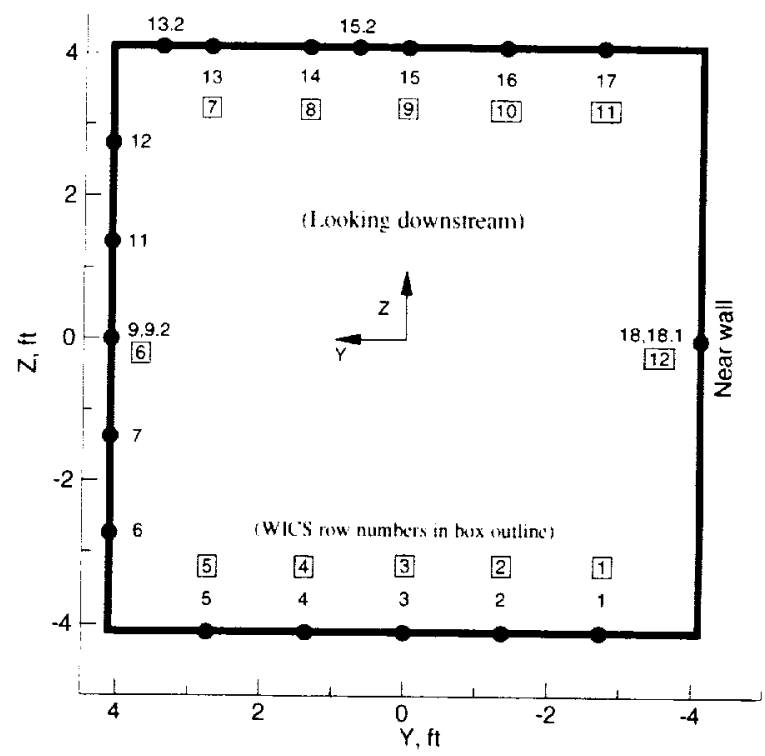

Fig. 1 Cross-Sectional Pressure Measurement Row Setup of the NTF 


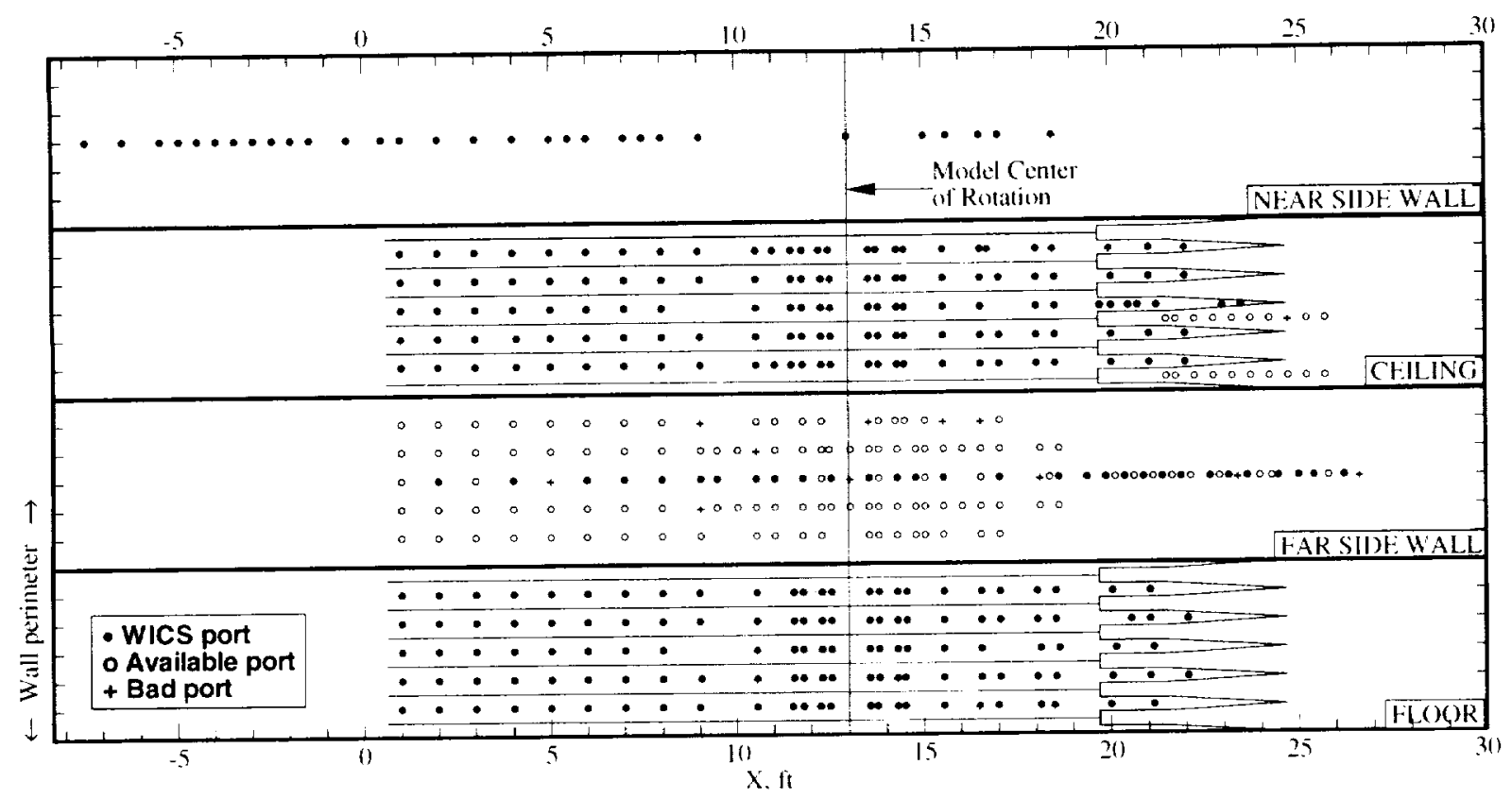

Fig. 2 Wall Orifice Layout for NTF

installed condition and the empty tumel. The test article is comprised of singularities: a source-sink combination is used to represent the fuselage: sources are used to represent the viscous separation in the wake; and line doublets. typically placed on a lifting surface quarter-chord, are used to simulate the effect of lift. Additionally, a powered simulation can be represented by proper placement of a sink. Once the strengths of the line doublets and propulsion simulation sinks are known. the signature of these singularities is sulbtracted from the tared wall signature. The remaining signature is used to determine the strengths of the solid and wake blockage singularities. Hackett ef al. ${ }^{12,13}$ originally used a "local" least squares fitting procedure of the wall pressure data, which was labor intensive because each pressure measurement used in the fit of the wall signature had to be individually selected for each data point. In an effort to improve the process, Ulbrich" introduced a "global" least squares fitting procedure that uses all available pressure ports. The use of panel cocles to precompute normalized solutions for use in matching the signature was also introduced. Ulbrich further modified the Hackett method by using balance measured fores and moments to calculate the strength of the doublet singularities. The method uses tared data to assess the wall induced effects on the test article. The tared data are obtained by subtracting empty tumel wall pressure port calibrations from the model-installed pressure data to remove first order effects of the empty tumnel boundary layer and buoyancy. This taring of the measured data assumes that the additional second order change in the bound- ary layer displacoment thickness due to the model in the tumel is negligible. Normalized perturbation volocities are calculated from the subsonic potential equation using the method of images. for each type of singularity in discrete locations in the tumnel. By superimposing these moded singularities with their corresponding calculated strengths. interference velocities are computed.

The blockage interference factor $z$ is defined by.

$$
\varepsilon=\frac{u_{i}}{L_{i}} \approx \frac{u_{T}-u_{F}}{l^{r}}
$$

where $u_{i} / l_{i}=\partial_{\varphi l} / \partial r$ and $\varphi_{l} \approx \varphi T-\varphi l$. Incidence and sideslip corrections are defined by

$$
\begin{aligned}
& \alpha_{i}=\frac{U_{t}}{U_{x}} \frac{u_{i}}{L_{t^{\prime}}} \approx \frac{U_{i}}{U_{x}} \frac{u_{T}-u_{T}}{U_{i}} \\
& \beta_{i}=\frac{U_{t}}{U_{x}} \frac{v_{i}}{U_{t}} \approx \frac{U_{t}}{U_{x}} \frac{V_{T}-\varphi_{T}}{U_{t}}
\end{aligned}
$$

where $E_{x} / E^{*}$ is dofined by $1+z$. It is important to note that the integrated offect of the empty tumnel boundary layer growth and buovancy duc to inproper wall divergence are already included in $L,$. The "empty-tumnel" calibration provides the perturbation velocity demoted by $u_{i}$, which ean be used to correct the measured modol-in-tumnel perturbation relocity. $u_{I}^{\prime}, \mathrm{ly}$

$$
\frac{u_{T}}{I_{C_{\prime}}}=\frac{u_{T}^{\prime}-u_{t}}{l^{*}}
$$

The ratio $u_{T} / V_{\text {e }}$ is used to determine the singularity strengths. 


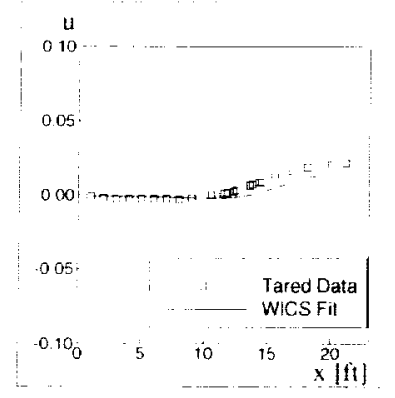

a) $\operatorname{Row} 1$.

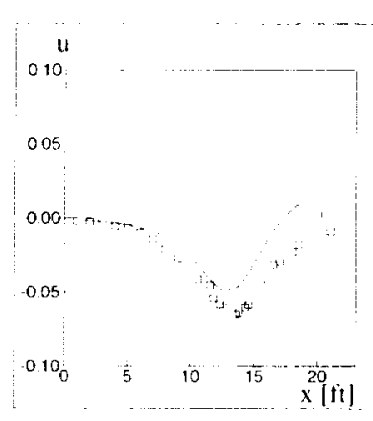

c) Row 5

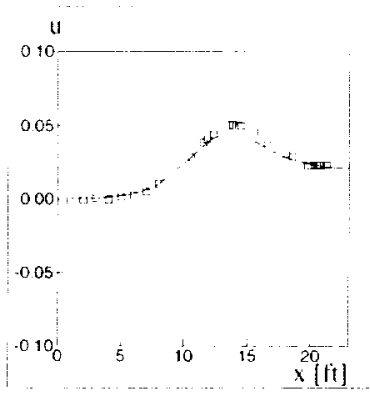

e) Row 9 .

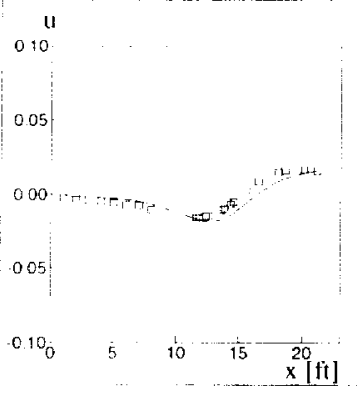

b) Row 3 .

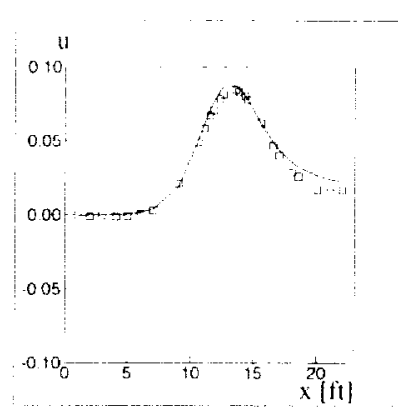

d) Row $i$.

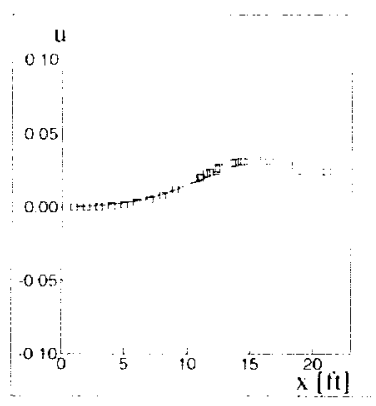

f) $\operatorname{kow} 11$.
Fig. 3 Wall Signature of a Low Aspect Ratio-High Lift-Semispan Model at $\alpha_{u n}=24^{\circ}$

\section{General Implementation Requirements}

To implement the WICS code." several tasks must first be completed. The first task is to ensure the facility has an adequate number of static pressure orifices on the wall of the test section. (The meaning of adequate will be discussed later in this paper.) Next, a perturbation velocity database (PVD) must be generated using a panel method or the method of images. This PVD is used in the matching of the tared wall signature to determine singularity strengths, and to generate the field of interference velocities so that corrections can be computed.

Once the orifices have been installed, an "empty tunnel" calibration must be performed. This calibration is a function of independent test parameters (e.g., total pressure and Mach number) and support system attitude (e.g., pitch and sideslip angles). For semispan models, the empty tumnel calibration is the tunnel geometry minus the model. For fullspan models the model support system is included, and the sting or support system kinematios must also be considered. Semispan and fullspan model installation details are provided subsequently.

\section{Code Output Results}

Figures 3 - 5 present a sample of the WICS rocle output from the NTF for a semispan model. Figure 3 gives a row-wise comparison of the tared signature with the WICS-fit wall signature for a single test point at $M=0.2, a_{u n u}=24^{\circ}$ for a semispan model. The symbols represent medsured, tared wall perturbation velocities and the solid line represents the global least squares prediction of the code. (One measure of validity is how well these two match.) Mean prinary corrections are displayed in Figure 4. These correc-

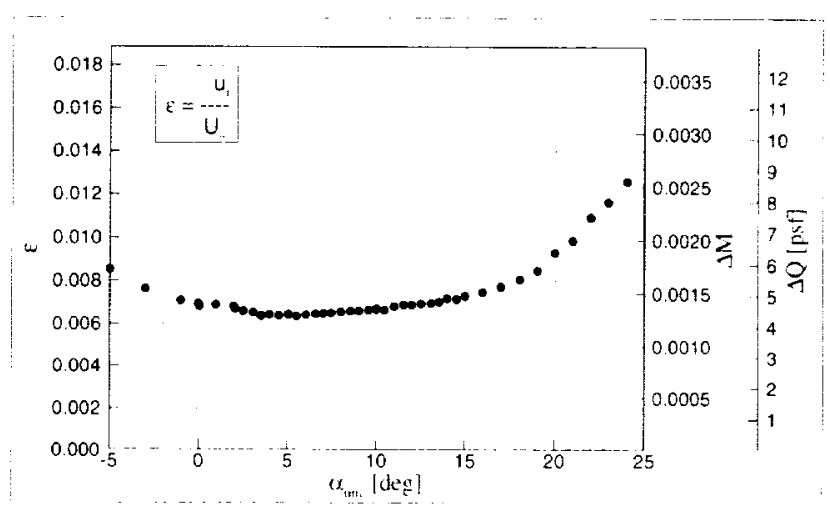

a) Blockage correction

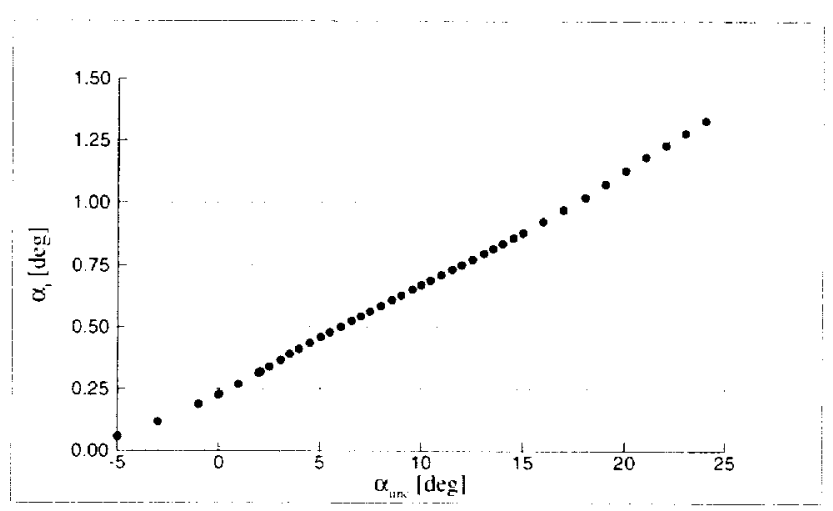

b) Incidence Correction

Fig. 4 Mean Primary Corrections for a Low Aspect Ratio-High Lift-Semispan Model

tions are shown for an entire pitch polar (or group of data points). Blockage corrections $(\varepsilon)$ are averaged interference velocities along the fuselage centerline, and upwash (incidence) corrections $\left(\alpha_{i}\right)$ are averaged along the wing three-quarter-chord. Corrections to Mach number $(\Delta M)$ and dynamic pressure $(\Delta Q)$ are derived from the blockage factor. Coefficient corrections for the entire polar are plotted in Figure 5. Note for the test point of $\alpha=24^{\circ}$ in Figure 3 that a blockage induced correction of $\Delta M=0.0025$ and a significant incidence correction of $\alpha_{i}=1.33$ are determined as shown in Figure 4. Correspondingly large corrections 


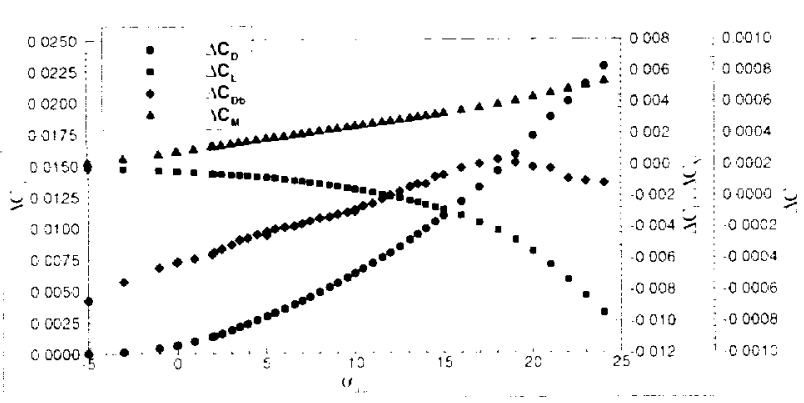

Fig. 5 Coefficient Corrections for a Low Aspect Ratio-High Lift-Semispan Model

for the roefficients are also observed (Figure 5). Since the WICS code calculates the interference corrections for specified reference planes in a velume surrounding the model. contours of the correction rariation can be plotted.

\section{Aerodynamic Parameter Sensitivities}

The purpose of this section is to understand how the WICS code responels to the independent rariation of Reymolds Number and Mach Number. (Note that NTF also allows the independent variation of dynamic pressure. but no data of this type were available for use in this study.)

\section{Reynolds Number}

As previously stated. boundary pressure methods allow inclusion of actual tumel response in the computation of wall effects. This is due to a response to the pressure change due to the boundary layer height changing, which is highy dependent on Reynolds number. This an easily be seen by plotting the total blockage factor. ET. against the uncorrected lift coefficient, Clame. for varying Reynolds numbers at a Mach number of 0.2 see Figure 6 ). Blochange les-

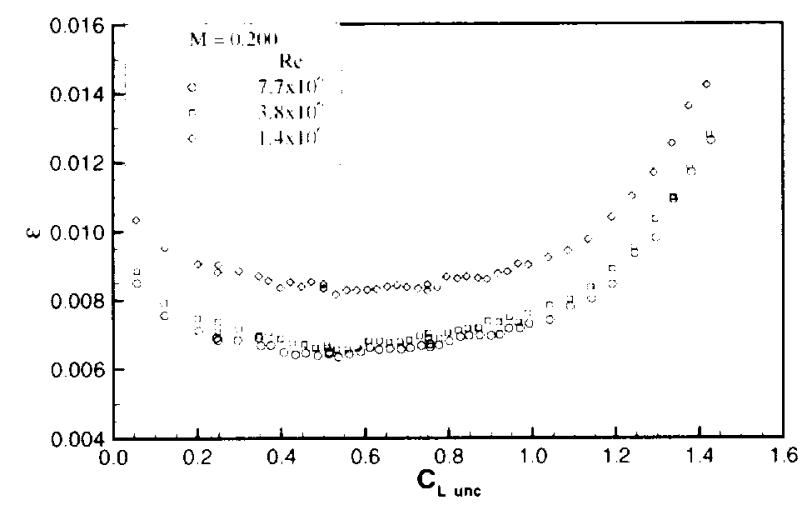

Fig. 6 Total Blockage Variation with Reynolds Number $(\mathrm{M}=0.2)$

els are inversely proportional to Reynolds number, due to higher Reynolds numbers causing thinner wall and model boundary layers, corresponding to an effective change in tumnel cross-sectional ared. Thus the
WIC'S code responds to the "soft wall" as opposed to the "hand wall" assumptions made in classical theory. If there is no correction for wall effects. a psendeReymolds number effect may be embedded in the wind tummel data.

\section{Mach Number}

According to classical wall interference theory. the blockage factor a should scale according to the Prandt]-Glauert compressibility factor 6 . Figure 7 shows the blockage factor over a data run for several Mach numbers. It can be seen that the valiation of $z$ ? at constant lift coctheient is not a linear function of Mach number; in fact. it is a function of order greater than or equal to three. Insutticient data exist to further evaluate this phenomena: therefore. this is and area for further study into the tumnel flow field to determine the somere of this phemonema.

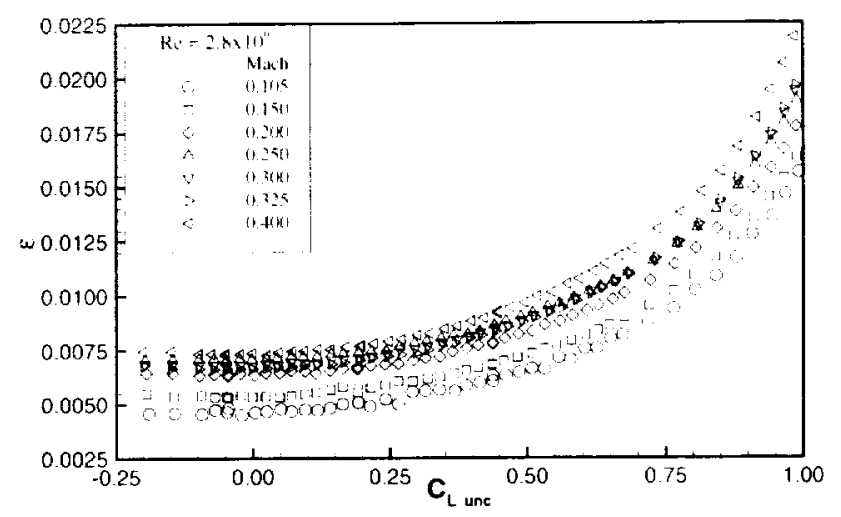

Fig. 7 Total Blockage Variation with Mach Number

\section{Support System Sensitivities}

The purpose of this section is to discuss the potential orror caused by support systems. Moclel supports for both fullspan and semispan models will be discussed.

\section{Fullspan Support Systems}

A major concern with the use of the WICS code in trumels is the cost of the fullspan support system calibration. While this is necessary to obtain modelonly wall interference corrections, it can be extremely expensive and on occasion unfeasible. Cibrich"t has developed an alternative method which does not resquire a support system ralibration for sting mounted models. His alternative method replaces the support system solid blockage source singularities by dhains of point doublets. These chains are placed along the support system centerline and are weighted according to the cross-sectional area distribution. This method does not currently work with post mounted models.

In terms of the code semsitivities, if the support system calibration can be shown to be negligible, it could be ignored and the true empty tumel data could be 
used in its place. Unfortunately, the interference induced by almost all fullspan support systems will cause a noticeable error in the corrections if they are neglecterl. This error in the corrections was also noted by Murthy. ${ }^{15}$

\section{Semispan Standoff}

Questions have been raised concerning the calculdtion of wall interference corrections with a semispan model standoff support system present. The standoff contributes to the blockage and lift interference in the tumel but is non-metric with respect to the balance. Since the WICS code incorporates data from both the wall pressures and the balance, an inherent inconsistency in the method of correction is introduced.

For a fullspan model the "empty tunnel" wall signature includes the support hardware, unlike the semispan technique. The pressure signature of the standoff cannot easily be identified and removed from the wall signature, if at all. The flow field produced by testing only the standoff is radically different than with the model installed creating an inconsistency dilemma. Two solution approaches are presented. First, depending on the type of testing, the standoff blockage may be neglected. Second, the lift on the standoff can be calculated so the bookkereping of interference becomes ronsistent.

Studies have been performed to simulate the lift interference of the standoff. A transport semispan model was tested in the NTF. Centerline fuselage pressures were measured. These pressures where integrated in the chord-wise direction around the fuselage to obtain a two-dimensional lift coefficient for each angle of attack tested. Milholen and Chokani ${ }^{16}$ have shown that the (hord $C_{P}$ distribution can be assumed to be ap)proximately constant from the fuselage centerline to the wall (i.e.. standoff root to tip) if the standoff is a two-dimensional extension of the fuselage centerline. ${ }^{17}$ These assumptions allow the span-wise integration of the chord lift across the width of the standoff, thus yielding a three-dimensional lift coefficient.

$$
C_{L_{s, 1}}=\oint C_{P} d\left(\frac{r}{l}\right) d\left(\frac{h}{b / 2}\right)
$$

Here $\frac{x}{r}$ is the percent chord and $\frac{h}{b / 2}$ is the height of the standoff normalized by the semispan. Figure 8 shows the magnitude of the calculated lift increment due to the standoff.

Test data were then corrected with and without the standoff lift increment. Figure 9 shows this correction comparison. Not including the lift of the standoff causes an over prediction in the blockage. This happens because the value of lift is changed and the corresponding singularities also change. The result of this increase in lift is that more lift interference is subtracted from tho wall signature, thereby, causing the blockage interference to be lower. Incroases are seen in

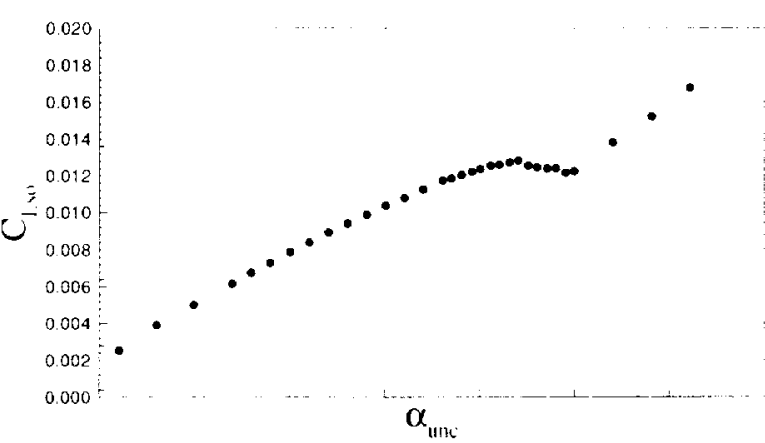

Fig. 8 Integrated Three-Dimensional Lift of a Two-Dimensional Semispan Transport Standoff

the incidence correction due primarily to the increase in lift.

Walker ${ }^{18}$ and Walker et al. ${ }^{19}$ have determined the sensitivity of the code to error in the lift measurement. Since the method of correction for the presence of the semispan standoff entails only a incremental adjustment to the measured lift, this can be treated as causing an error to occur in the lift measurement. Given this logic, correction for the presence of the semispan standoff may be safely neglected when the lift generated by the standoff falls within the generalized correction accuracr requirements given in Talle 1.

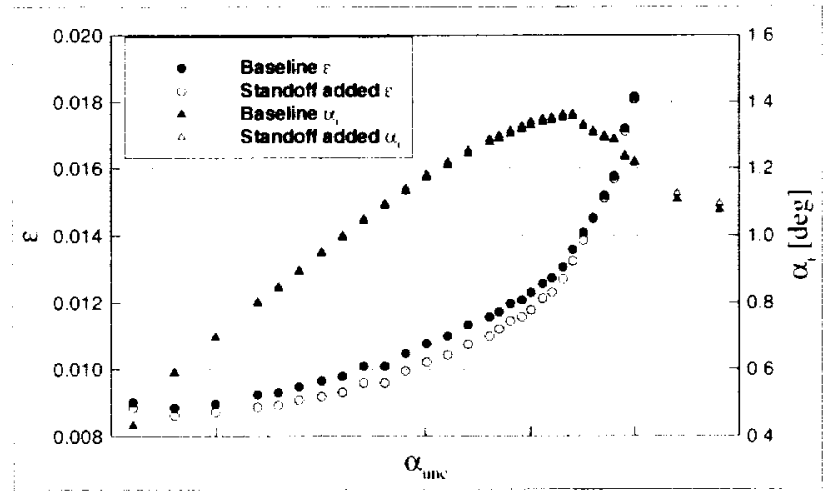

Fig. 9 Effect of Standoff Lift on Primary Corrections

\section{Other Sensitivities}

In an effort to reduce the influence of outlying data on the global least squares solution, a data rejection algorithm was implemented in the WICS code. This section addresses the standard data rejection algorithm of the WICS code. The primary topic of discussion will be the algorithm's interaction with the sensitivities. Two different types of improvements are suggested. The first involves a more statistically meaningful rejecction algorithm, and the second involves a more robust matrix solver that is not easily biased by outlying data.

\section{Standard Data Rejection Algorithm}

Currently, the algorithm rejects data based on two criteria. The first test performed is an absolute range 
cherk. If wall signature data exceeds $20 \%$ of the corresponding empty tmmel calibration. these data are not used in the correction calculation. The serond test attempts to korate and remove outliers. It does so by ealculating the average difference between the tareet wall signature and the wies fit. Data whose absolute difference is greater than 3 times the RMIS of the average difference are removed from the calculation. Essentially, the classical form of the standard deviation is used and data which lie more than three standard deviations from the mean are rejected. The samplo variance is computed as follows:

$$
s^{2}=\frac{\sum\left(u_{t u n_{i}}-u_{f i t}\right)^{2}}{N-P-1}
$$

where $u_{\text {tun, }}$ is the measured in tumnel perturbation velocity. $u_{f}$, is the "alculated least sequares tit of $u_{f u n_{i}}$, $N$ is the number of active ports, and $P$ is the number of parameters or dimensions in the solution process. Note that in the original version of WICS the value of $P$ was set to zero, but this had very little effect on the calculated variance due to the large value of $N(260-290$ in NTF $)$. Onee these tests are performed, the calculation procelure is only allowed to continue if more than 60 port ralues remain in the ralculation. The flow field is then split into three parts: upstrean of the model, around the model, and downtrean of the model. The artive wall pressure port distribution is calculated and reported as a percentage of the total active ports in cach area of the flow fichel

The data rejection algorithm was raluaterl following some concern that valid data were being discarded. Normally this would not be an issue since the WICS code computes a global least squares fit of sevoral hundred wall pressures using the method of singular value decomposition to determine the blockege singularity strength and thereby the blockage. So the loss of a relatively small number of valid data points basically has little to no effect on the solution. Howerere the port placement sensitivities were defined bx Walker ${ }^{18}$ and Walker of al. ${ }^{19}$ and regions of ritical moasurements wore established. Ports around the model and wake singularities are implicitly weighted more heavily than those further upstream or downstroam. The implicit weighting approximately varies as the inverse of the sepuare of the distance from the singularity to the wall port for sources (i.e., influence decays quickly with distance). The implicit weighting for doublets decays as the inverse of the eube of the radial distance from the singularity to the wall port. Accordingly, the loss of malid moasurements in regions of relatively strong influence can adversely affect the sensitivities of the output corrections.

The effect of the data rejection algorithm on the wall signature is shown in Figure 10. This figure contains four representative rows of data near the model (Figures 10a-10d) and a break out of wall signature

components for a row (Figure 10e). The filled circles represent data that were retained after execution of the data rejection algorithm. Data that were rejected are indicated by the open circeles. The solid line is the WIC'S rakulated fit of the retained data. The code was again executed but foreed to keep all wall data. This ricleded a fit of all the data or the total fit. which is denoted by the dashed line.

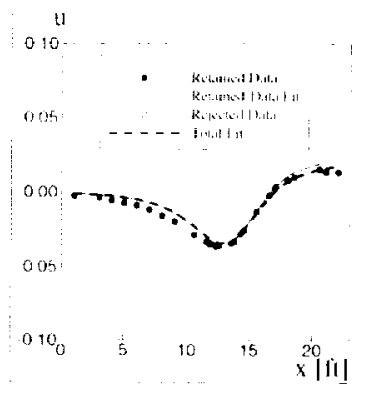

a) Row 1 .

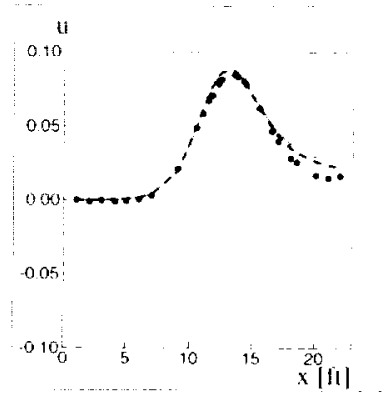

c) Row $i$.

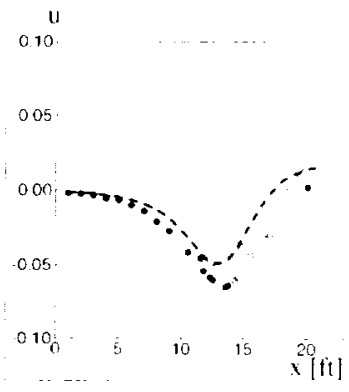

b) Rim $\therefore$.
(1)

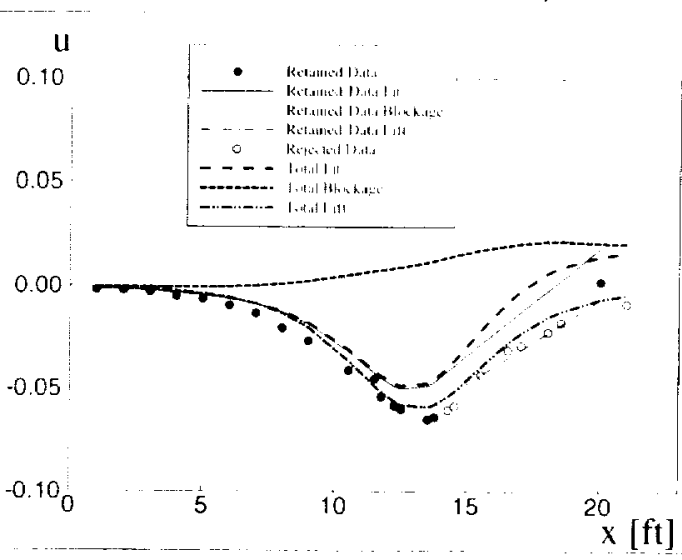

e) Row 5 with lift and Blockage Components.

Fig. 10 Data Rejection Algorithm Effect on the Wall Signature of a Low Aspect Ratio-High LiftSemispan Model at $a_{u n}=24^{\circ}$

As can be seen from Figure 10e, resolution of the wall signature is lost when wall clata are rejected. This is evidenced by the straight line connection among the rejected data in the retained data curves. Since the only rhange between the two cases is the inclusion of wall data that would have otherwise been rejected. the doublet strengths representing the lift component of the wall signature remain unchanged. Even though the' 
strengths remain the same, the lift signature changes when all the wall measurement points are included because the wall flow ficld has been resolved in finer detail. This in tum has a direct impact on the least squares solution of the solid and wake blockage singularities since a different value for the lift interference has been subtracted at the previously rejected ports. The afferet of the data rejection algorithm on the primary corrections is shown in Figure 11. The overall result is that rejection of the valid data near the model singularities caused the code to over predict blockage and. in turn, the correction to model incidence. The conchusion is drawn that when valid data in regions of high sensitivity are discarded a true global solution (aumot be determined.

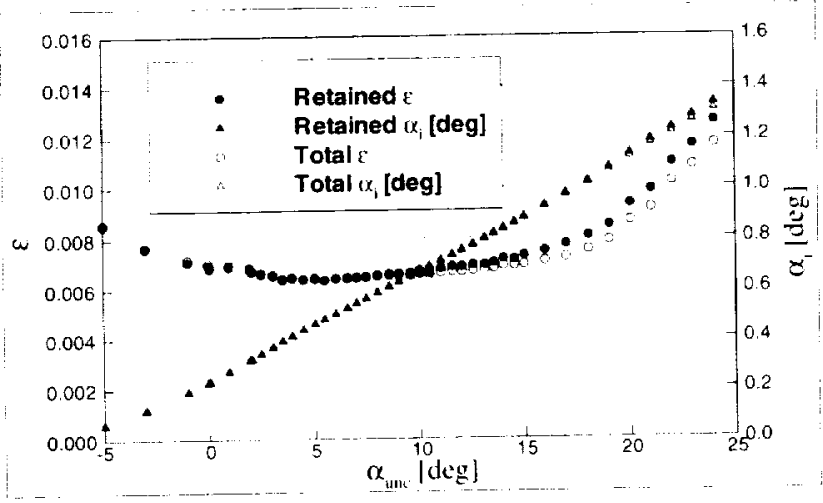

Fig. 11 Data Rejection Algorithm Effect on the Mean Primary Corrections of a Low Aspect RatioHigh Lift-Semispan Model

\section{Improved Data Rejection Algorithm}

Taking into account the regions of high sensitivity near the model singularities and the WICS mathematical model, a modification to the calculation of the standard deviation has been developed to improve the data rejection algorithm. The WICS mathematical model contains two descriptive variables with no constant term

$$
\mathbf{A}_{N \times 2}\left(\begin{array}{c}
\sigma_{*} \\
\sigma_{* *}
\end{array}\right)=\mathbf{B}_{N \times 1}
$$

where the elements of $\mathbf{A}$ are determined from the PVD, the elements of $\mathbf{B}$ are determined by subtracting all but the blockage component from the measured wall data, and the elements $\sigma_{*}$ and $\sigma_{* *}$ are the solid rolume and viscous wake blockage singularity strengths, respectively.

One of the major issues is that the residuals $\left(u_{t_{u} n_{i}}-\right.$ $u_{f i t}$ ) are not normally distributed. From this, it can be inferred that $u_{f i t}$ is not the true mean of the wall data. This fact is quite possibly due to the low order of the mathematical model of the flow field (i.e., there are insufficient degrees of freedom in the mathemati(al model to allow for the solution of the true mean. even if no error is present in the data). Given this reasoning, it is easily understood why the data in Fig- ure 10 were rejected. Cse of $u_{f i t}$ as the sample mean has biased the calculation of the standard deviation, thereby under-inflating the confidence interval set to reject data. Now that it is nnderstood that $u_{f}$ it is a biased estimat or for the sample mean of $u_{t u m}$, a better estimate of the confidence interval can be constructed by assuming that $u_{f i}$ is a low-order estimate of the sample mean. This means that the corresponding degrees of freedom in the solution should be reduced such that a proper inflation of the confidence interval can be achieved. The reduction in the number of degrees of freedom can be arhieved by considering the implicit weighting of the singularity strengths based on the radial distance from the model singularities to the wall pressure ports.

Define $r_{*}$ as the minimum raclial distance from a singularity to a wall pressure port. Then a weighting (II) of the influence each wall pressure port has on the solution can be determined for a source by

$$
\Pi_{i}=\frac{r_{*}^{\cdot 2}}{r_{i}^{2}}
$$

and for a doublet by

$$
\Pi_{i}=\frac{r_{*}^{3}}{r_{i}^{3}}
$$

The number of effective wall orifices $\left(N_{u}\right)$ in the tumnel is calculated by summing the influential weights of each orifice

$$
N_{u}=\sum_{i=1}^{N} H_{i}
$$

Philosophically, If should be determined for each singularity solved for, $\sigma_{*}$ and $\sigma_{* *}$, and the number of effective wall ports, $N_{u}$ is the difference between the union and intersection of the sets.

$$
N_{u^{\prime}}=W_{i_{\sigma_{*}}} \cup H_{i_{\sigma_{* *}}}-H_{i_{\sigma_{*}}} \cap \mathrm{H}_{i_{\sigma_{* *}}}
$$

where $H_{i}$. and $W_{i_{* *}}$ denote the set of weights for each wall port based on the distance to the respective singularity. The sample variance is then calculated by

$$
s^{2}=\frac{\sum\left(u_{t u n_{i}}-u_{f i t}\right)^{2}}{N_{u}-P-1}
$$

where $P$ is the number of parameters or descriptive variables in the mathematical model, for the WICS code $P=2$. Use of this method allows a more proper inflation of the confidence interval such that data which are truly outlying and have a potential of biasing the solution will have a much better probability of detection and removal.

\section{Solutions using Robust Regression Techniques}

As an alternate solution to the problem of ontlying data, robust regression methods have been evaluated 
for use in solving the solid volume and viscous wake blockage singularity strengths. The methods of Least Median of Squares (LMS) and Least Trimmed Squares introduced by Rousseeuw and Lerove were malyzed as potential matrix solvers for the IIICS code. Use of these techniques allows the solution some level of insensitivity to error in the moasured clata. There are. however, some clisadvantages to using these terdniques with this type of modeling or simulation. These will ho discussed after a presentation of the basic methods. To facilitate an casier comparison of the regression techniques, a brief description of the least squares method is included.

Consider a general linear model with $P$ explanatory variables, one response variable, and $N$ rlata points. This model can be expressed as

$$
\mathbf{Y}_{\mathrm{N} \times 1}=\mathbf{D}_{\mathrm{x} \times r}, \mathbf{X}_{r \times 1}+\mathbf{E}_{\mathrm{N} \times 1}
$$

where $Y$ is the response mariable. $D$ is the matrix of explanatory variabless. $\mathrm{X}$ is the solution vector of coefficients, and $\mathbf{E}$ is the vector of errors. which is classically assumed to be normally distributed with mean of zero and unknown variance $\sigma^{2}$. The relation for the solved estimation is expressed as

$$
\hat{\mathbf{Y}}_{N \times 1}=\mathbf{D}_{N \times,}, \hat{\mathbf{X}}_{r \times 1}
$$

where the hat denotes an estimated parameter or variable. From these expressions the matrix of residuals is defined as

$$
\mathbf{R}_{N \times 1}=\mathbf{Y}_{\lambda \times 1}-\hat{\mathbf{Y}}_{N \times 1}
$$

The method of least squares (LS) then corresponds to

$$
\text { Minimize } \sum_{j=1}^{N} R_{j}^{2} \text { based on } \hat{\mathbf{X}}
$$

An important topic of discussion is the notion of a breakdown point. Basically: the breakdown point of a regression method corresponds to the percentage of contamination allowed in the data set such that if an exact fit exists the method is able to resolve it. For the LS method. its breakdown point is $0 \%$. In other words, if there exists any data contamination the LS method will not resolve an exact fit.

Unlike the me'an of a set of clata that is influenced easily by any outlying data, the median is very robust. This is the basis for the LXIS method which can be expressed as

$$
\text { Minimize median, } R_{j}^{2} \text { based on } \hat{\mathrm{X}}
$$

The brokdown point of the LMS method is $50 \%$, which is the highest possible value: unfortmately, Rousseeuw has shown that LMS has an abnormally slow convergence rate. In an effort to increase the convergence rate, he introduced the LTS methed. This method is given by

$$
\operatorname{Minimize} \sum_{j=1}^{\prime \prime}\left(R_{j}^{2}\right)_{j: N} \text { based on } \hat{\mathbf{X}}
$$

where $\left(R^{2}\right)_{1} \leq \cdots \leq\left(R^{2}\right)$, w are ordered scpuared residuals. The LTS method is similar to LS with the exception that the largest residuals are not included in the calculation. This is the so called trimming of the LS method. The breakdown point of the LTS methed depends on the value chosen for $h$. A breakdown point of $50 \%$ is achieved when $h$ is approximately $n / 2$.

The matrix solver in the WICS code was replaced with both a LMS and LTS solver for comparison. The algorithms were adapted from the Program for Robust Regression (PROGRESS) described by Roussemw and Leroy ${ }^{20}$ and improved by Rousserew and Hubert. ${ }^{21}$ The breakdown points for both methods were set to $25 \%$ for reasons discussed below. The computation time of the full LAS and LTS mothods is extremely slow compared to the WICS LS calculation. Sincer spered of computation was one of the main reasons for the rhoice of the WICS code. a serere increase in computation time is not desirable. Fortunately. Rousserem and Van Driessene2-2 have developed a LTS approximation algorithm (FAST-LTS) that executes at approximately the same speed as the standard WICS LS methosl.

Figure 12 details a comparison of the wall signature computed from the various methods. and Figure 13 show the resulting primary corrections. At this time no tinal conchusions have been drawn concerning the use of robust regression methods in the WICS code. There were. however, some important olservations. Since the mathematical model in the IIICS code (refer to Equation 7) has been reduced to a simplistic representation of the flow field, use of high-breakdown point regression estimators may also result in the insensitivity to certain local phrsical fluid drnamic phenomena due the large residuals produced when the mathematical model camot be fored to fit the measured data. The combination of this insensitivity effect and the lack of resolution of the wall signat ure far downstream of the model and wake in NTF resulted in the selertion of a $25 \%$ breakdown point for the LMIS. LTS, and FAST-LTS methods. The high-breakdown point regression methods are anticipated to perform better for the WICS implementation at the XASA Langley 14-bs 22-Foot Subsonic Tunnel $(14 \times 22)$ due to a proposed increase in the resolution of the wall signature far down stream of the model. Inplementation of the WICS rode at $14 \times 22$ is discussed by Iyer and Everhart. ${ }^{2.3}$ Another important observation was the strong agreesment between all the mothods in regions where little or no separated flow occurred. This is indicative of the greater uncertainty involved in the computation of flow fields with regions of separated How. 


\section{Conclusions}

This paper makes several general conclusions concerning the WICS code. The code appropriately responds to changes in Reynolds number. Some question arose as to the codes response to Mach mumber changes at constant Revnolds mumber. but additional data are required to further investigate the true response.

Fullspan support systems almost always create enough blockage that they must be accounted for by sonf method. For semispan models using a standoff, a correction to the lift based on the stancloff is necessary if the standoff lift is predicted to generate more lift than the generalized correction accuracy requirements allow. Typically this entails a standoff lift greater than one-half of the absolute correction accuracy requirements or $0.2 \%$ of the model generated lift.

It was also conchuded that there were circumstances in which the standard datal rejection algorithm of the WICS code rejected valicl data which had an influence on the sensitivities of the corrections. To aroid this problem an alternate rejection algorithm was proposed. In an attempt to completely circumvent the rejection algorithm an evaluation of robust regression estimators was begun. No final conclusions were made for the use of a robust regression method in the WICS code. but several findings were presented. More analysis should be performed to properly assess the use of these methods in this type of engineering data analysis.

\section{References}

I (iamer. H., Rogers, E., Acum. W., and Maskell, E., "Subsonic Wind Tunnel Wall Interference Corrections," ACARDograph 109, October 1966.

"lwald (Editor), B. F. R., "Wind Tumel Wall Corrections," A(iARDograph 336, () tober 1998

${ }^{3}$ Iver, V., Everhart, J., Bir, P.. and Ulbrich, N., "Implenentation of the WIC'S Wall Interference Corrections System at the National Transonic Facility,"June 19-22 2000. Presented at the 21st AIAA Actodynambic Measurement Technology and Ground Testing Comference, MIA Paper 2000-2383.

lulbrich, $N$. and Lo, $(*$ " "A Wall lnterference Assess ment/Correction System," Semi-Annual Report \#1, The Iniversity of 'Pennessee space Institute, December 1991.

"Elbrich, K.. Lo, C., and F.W. Steinle, J., "Blockage Correction in Three-Dimensional Wind Tumel Festing Based on the Wall Signature Mothod," July 6-8 1992, Presented at the AIAA 17 th Arospace Ground Tisting Conference, NIA Paper $92-3925$.

${ }^{6}$ Elbrich. N. and Steinle, Jr., F.. "Reral-Time Wall Intcrforence Calculation in Three-Dimensional Subsonic Wind Tunnel Testing," January 10-13 1994, Presented at the 32nd Aerospace Sciences Meeting and Exhibit, AIA Paper 91-0771.

${ }^{7}$ Librich, N. and Steinle, Jr., F., "Semispan Model Wall Interference Prediction Based on the Wall Signature Method," January 9-12 1995, Presented at the 33rd Aerospace Sciences Meeting and Exhibit, ALA Paper 95-0793.

"Ufbrich, $\mathrm{X}$. and Boone, A., "Real-Time Wall Interference correction Sivstem of the 12FT Pressure Wind Tunnel," January 12-15 1998, Presented at the 36th Acrospace Sciences Meeting and Exhibit, NIA Paper $98-0707$.
${ }^{9}$ Tlbrich, N.. "The Real-Tine Wall Interference correction System of the NASA Ames l2-Foot Pressure lumnel," NASA (1) 1998-208537, 1998.

"sucinke, F. and Stancwsky, E.. "Wind Tumel Flow Quality" and Data Accurary Requirements." ACARD AR 184, November 1982.

${ }^{1}$ Fuller. D., (iloss, B., and Nystrom, 1)., "Guicle for lisers of the National Transonic lacility," NASA TA $8: 3121$. July 1981.

12 Ilackett. J. and Wilselen. 1)., "Estimation of Wind Tumnel Blockage from Wall Pressure Signatures: A Review of Recent Work at Lockheed-Ceorgia." AIA Paper 78-828, April 1978.

IsHarket1, I. Wilsden, D., and Sitevens, W. "A Review of the "Wall Pressure Signature" and Other limnel Constraint correction Methods for High Angle-of-Attack l'ests," A(i)Rl) R for2, Fobruary 1981. Presented to the AGALD Fluid Dynamics l'anel Round Table lisaussion on Wind Tunncl Comections for High Angle-of-Attack Models: Munich. FRC: 8 May 1980.

1.4 Clbrich, $X$ and Boone, A., "I petermination of the Nall Boundary Condition of the NASA Ames IIft Transonic Wind 'lunnel," Jamuary $x-112001$, Hesented at the 39th Aerospace sciences Mexting and Exhibit, NIA Paper 2001-1112.

15 Murthy, A.. "Wall and Support Interference Calculations Ising PAVCOR." June l993. Contract Report, ('ontrace NAil$1858 \%$.

16 Milholen, Wr and Chokani, N., "Computational Anatysis of Semi-Span Model Test Techniques." NASA C:R 1996-1709. 1996.

17 Gatlin, (i.. Parker, P'., and Owens, L., "I)evelopment of a Semi-Span Test Capability at lhe National Transonic Facility" AJA Paper $2001-0759,2001$.

IN Walker. E., Sensitivity of the Wall Interference Corre:ton System to Measurement Vncerlanty, Masier's thesis. The George Washington liniversity. 2000.

"Walker. E... Everhart. J., and lyer. V., "Sensitivity Sundy" of the Wall Interference (orrection System (WICs) for Rectangular 'lumbls." lanuary $8-112001$, Presented at the igth AlA Aerospace Sciences Meting and Exhibit. AlAA Paper $2001-0159$

20 Rousseeuw. P' and Leroy, A. Robast Regression and ()utLier Detection. John Wiley 8 Sons, 1987.

${ }^{2}$ Rousseeuw, I' and Huber1, M., "Recent developments in PROriRFss," 1997. Apperared in $L_{1}$-Statical Procedures and Related Topics. ed. by Y. Dodge. Institute of Maihematical Statistics Iecture Notes-Nonograph Series, Volume 31. Hawward, (A, pp. 201-211. Avalable from http:/ winwwot uta.ache a/statis.

22 Rousserew, $P$. and Driessen, K. V., "Computing LTS Regression for Large Dala Sets." 1999, Technical Report. Dniversity of Bntwerp. Available from http:/winwww.uia.ac.be $/ u /$ statis.

23 lyer, V. and Everhart, J.. "Application of Pressure-Based Wall Correction Methods to Two NASA Langley Wincl Tunnels," June 11-14 2001. Presented at the 19th AIAA Applied Acrodynamics Conference, AJA Paper 2001-2172. 


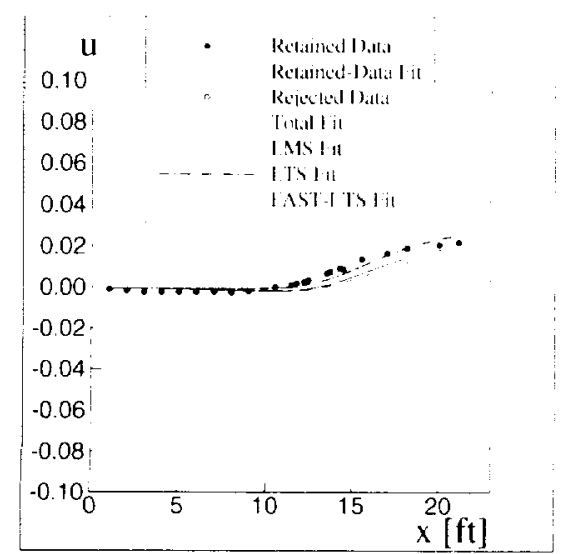

a) Row 1 .

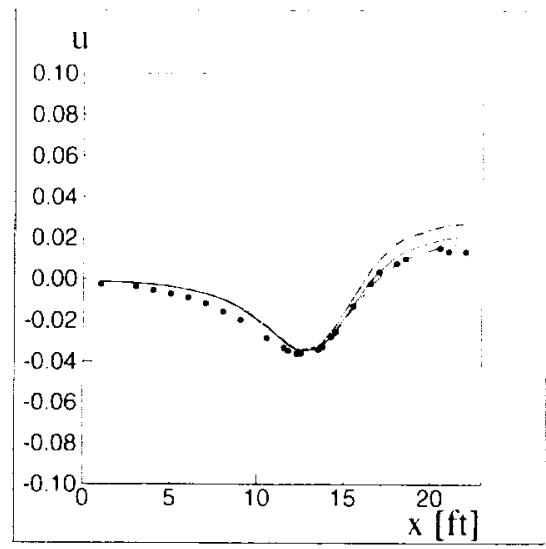

d) $\mathrm{Row} 1$

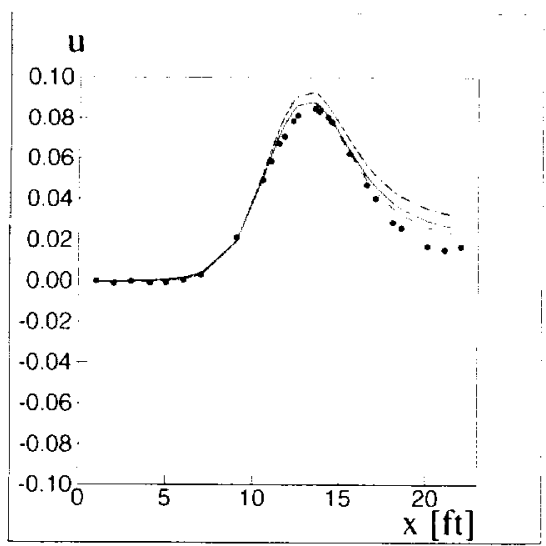

g) Row $i$.

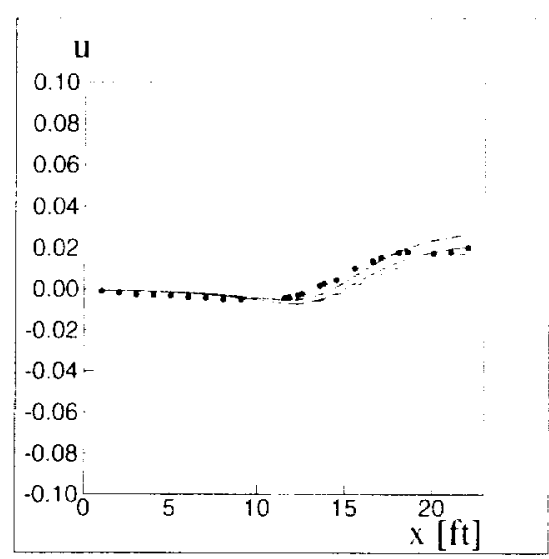

b) Ruw 2 .

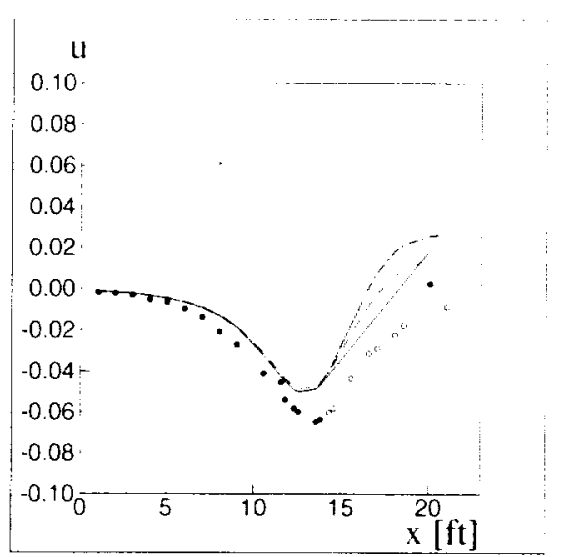

e) How 5

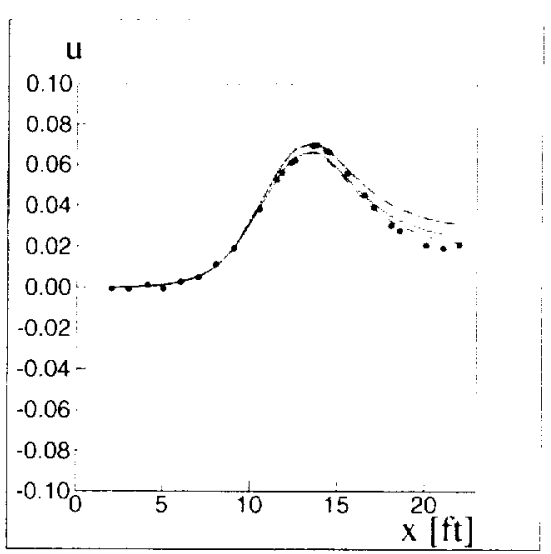

h) Row 8 .

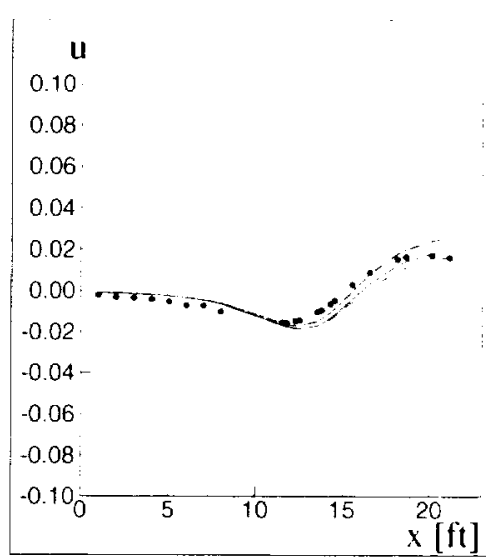

c) Row 3.

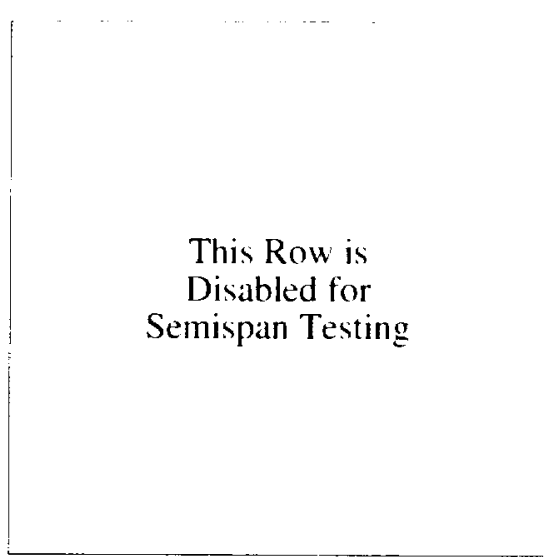

f) $R \mathrm{r} w 6$

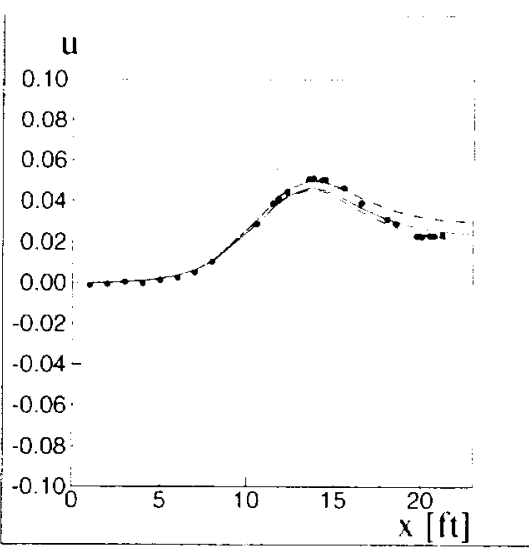

i) Row: 3

Fig. 12 Comparison of Solution Algorithm Effects on the Wall Signature of a Low Aspect Ratio-High Lift-Semispan Model at $\left(k_{u m}=24^{\circ}\right.$ 


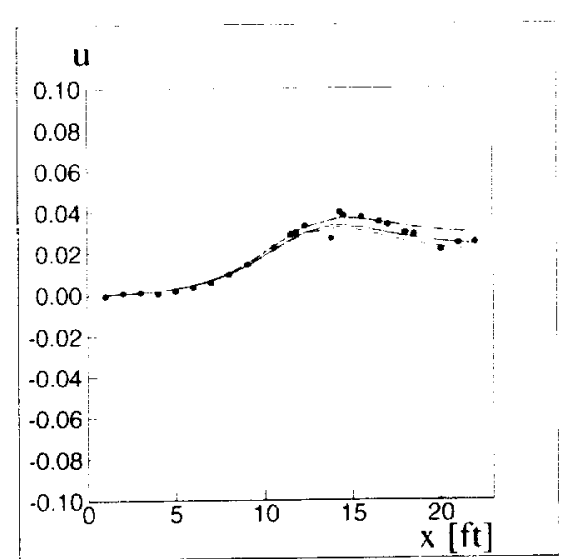

j) Row 10 .

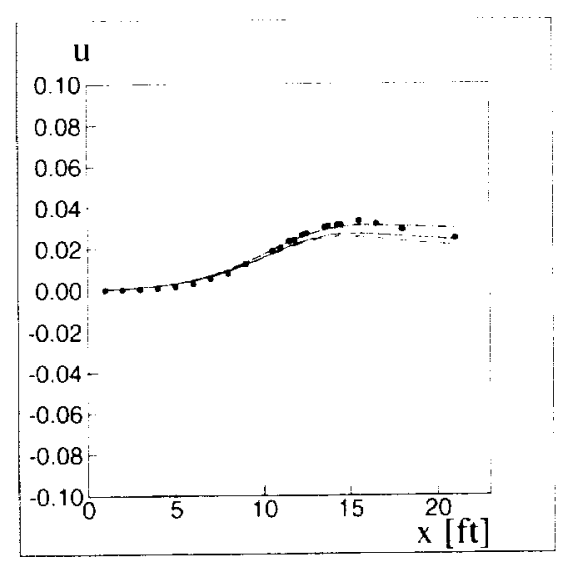

k) Row 11 .

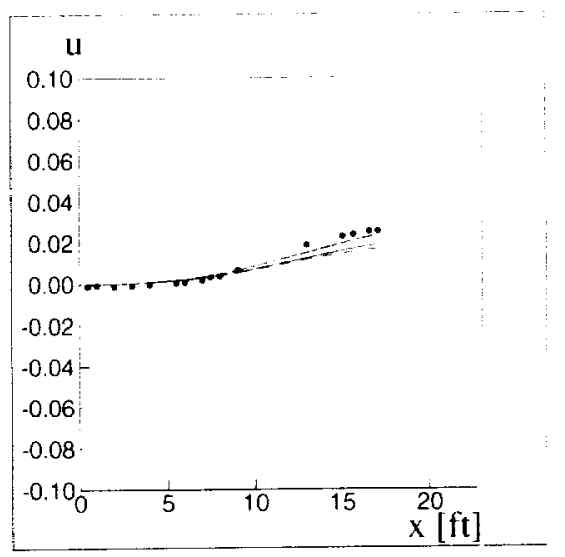

1) $\operatorname{Row} 12$

Fig. 12 Concluded.

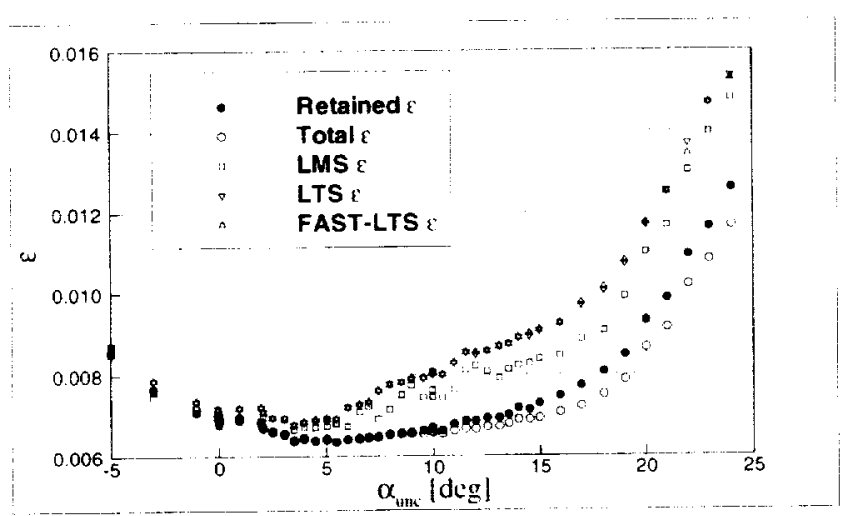

a) Blockage Factor.

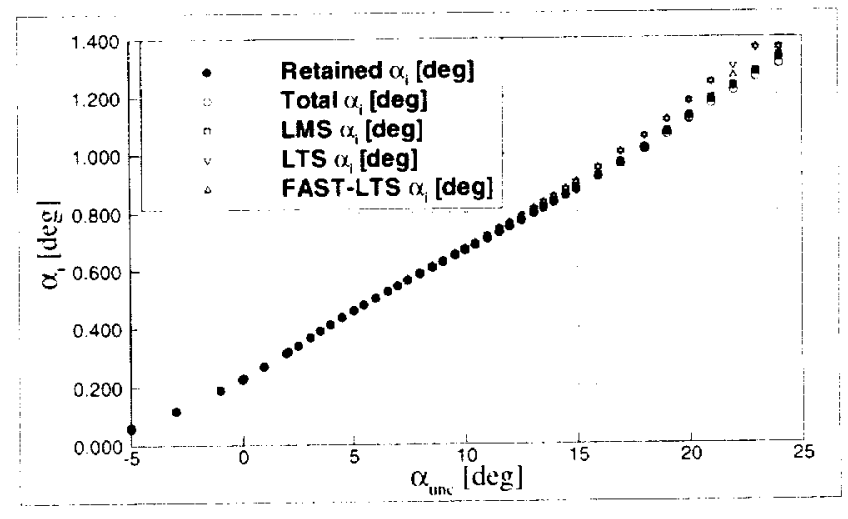

b) Incidence Correction.

Fig. 13 Comparison of Solution Algorithm Effects on the Primary Corrections of a Low Aspect RatioHigh Lift-Semispan Model 